\title{
触 New Disease Reports \\ Outbreak of anthracnose on apricots caused by Colletotrichum fioriniae in Slovenia
}

\author{
A. Munda* \\ Agricultural Institute of Slovenia, Hacquetova 17, SI-1000 Ljubljana, Slovenia \\ *E-mail: alenka.munda@kis.si
}

Received: 01 Sep 2015. Published: 07 Jan 2016.

In 2012 and 2013 apricots (Prunus armeniaca) showing circular, brown and slightly sunken necrotic lesions on the fruit surface were observed in commercial orchards near Nova Gorica (western Slovenia). When placed in humid conditions conidiomata with orange conidia masses developed on the lesions. Symptoms were most conspicuous on mature fruits at harvest time. The disease affected up to $10 \%$ of the fruits and was most severe in locations with high humidity. Twelve isolates were obtained by culturing pieces of infected tissue on potato dextrose agar (PDA). Single spore isolates were prepared and grown on PDA at $21^{\circ} \mathrm{C}$ and a 12 hour photoperiod. Colonies that developed after 10 days of incubation were white to light grey on the upper side and brownish pink to vinaceous with black spots on the underside. Average growth rate was $8.1 \mathrm{~mm}$ per day. Conidia were cylindrical to fusiform and pointed at both ends. They measured $7.5-16.7 \mu \mathrm{m}$ (mean $13.1 \mu \mathrm{m})$ x $3.5-4.9 \mu \mathrm{m}$ (mean $4.1 \mu \mathrm{m}$ ) Based on morphological characteristics the isolates were assigned to the Colletotrichum acutatum species complex (Damm et al., 2012). Five isolates were selected for further identification. Total DNA was extracted and a fragment of the $\beta$-tubulin-2 gene (exons 2-6) was amplified with primer pair T1 (O’Donnell \& Cigelnik, 1997) and Bt-2b (Glass \& Donaldson, 1995) and was sequenced (Macrogen, The Netherlands). Blast analysis showed that all isolates were the same and had $100 \%$ identity to several $C$. fioriniae strains deposited in GenBank including the ex-holotype strain CBS 128517. One sequence was deposited in GenBank (Accession No. KR061457).

Pathogenicity was tested by inoculating surface-sterilised apricots (cv. Bergeron) each with $10 \mu \mathrm{l}$ of a suspension of conidia $\left(10^{6}\right.$ conidia $\left.\mathrm{ml}^{-1}\right)$ obtained from a single spore culture. Five mature fruits were woundinoculated with a spore suspension and sterile distilled water was used for controls. After 10 days of incubation at $23^{\circ} \mathrm{C}$ at $100 \%$ relative humidity similar symptoms to those observed in the field developed around the inoculation point and $C$. fioriniae was re-isolated from inoculated fruits. No symptoms were observed on controls.

C. fioriniae, a member of the C. acutatum species complex, occurs in several fruit production regions worldwide. It has a broad host range and occurs on a wide variety of fruit crops. In Slovenia it has already been recorded on pome and small fruits as a causative agent of bitter rot of apples and ripe rot of high-bush blueberries (Munda, 2014). Here we report of the first finding of this pathogen on apricots. Further studies are required to reliably assess the potential threat posed by this pathogen for stone fruit production in Slovenia.

\section{References}

Damm U, Cannon PF, Woudenberg JHC, Crous PW, 2012. The Colletotrichum acutatum species complex. Studies in Mycology 73, 37-113. http://dx.doi.org/10.3114/sim0010

Glass NL, Donaldson G, 1995. Development of primer sets designed for use with PCR to amplify conserved genes from filamentous ascomycetes. Applied and Environmental Microbiology, 1323-1330.

Munda A, 2014. First report of Colletotrichum fioriniae and C. godetiae causing apple bitter rot in Slovenia. Plant Disease 98, 1282. http://dx.doi.org/10.1094/PDIS-04-14-0419-PDN

O’Donnell K, Cigelnik E, 1997. Two divergent intragenomic rDNA ITS2 types within a monophyletic lineage of the fungus Fusarium are nonorthologous. Molecular Phylogenetics and Evolution 7, 103-116. http://dx.doi.org/10.1006/mpev.1996.0376

\section{Figure 1}

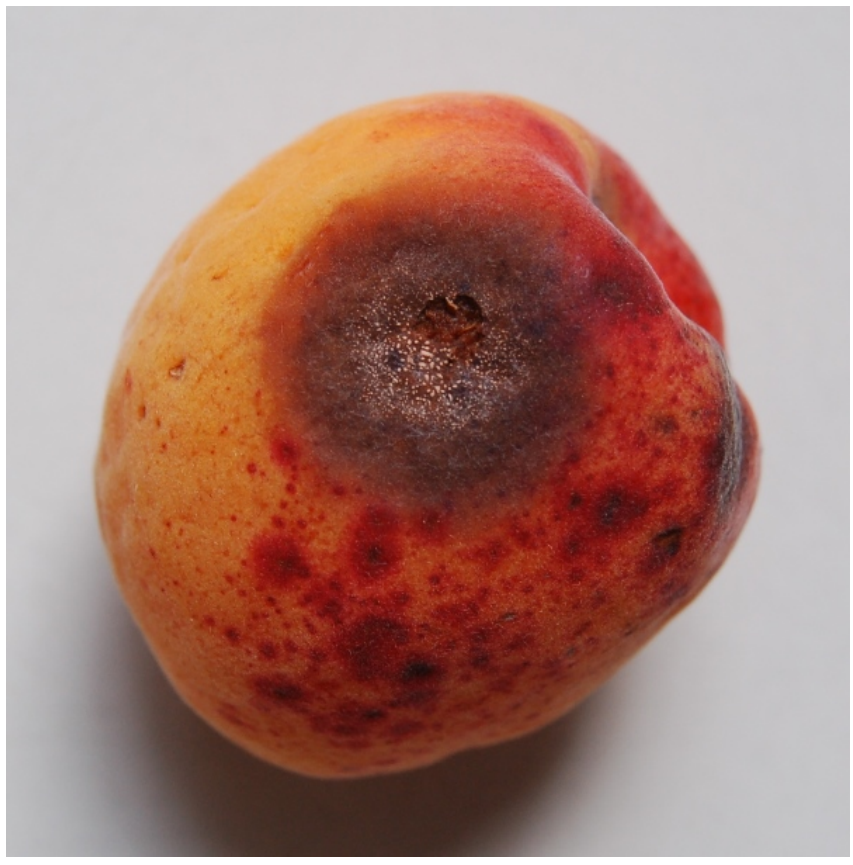

To cite this report: Munda A, 2016. Outbreak of anthracnose on apricots caused by Colletotrichum fioriniae in Slovenia. New Disease Reports 33, 2. http://dx.doi.org/10.5197/j.2044-0588.2016.033.002 